\title{
A highly reversible, low-strain Mg-ion insertion anode material for rechargeable Mg-ion batteries
}

\author{
$\mathrm{Na} \mathrm{Wu}{ }^{1}$, Ying-Chun $\mathrm{Lyu}^{2}$, Rui-Juan $\mathrm{Xiao}^{2}$, Xiqian Yu${ }^{3}$, Ya-Xia Yin ${ }^{1}$, Xiao-Qing Yang ${ }^{3}, \mathrm{Hong}^{2}$, \\ Lin $\mathrm{Gu}^{2}$ and Yu-Guo Guo ${ }^{1}$
}

Rechargeable magnesium $(\mathrm{Mg})$ batteries have been attracting increasing attention recently because of the abundance of the raw material, their relatively low price and their good safety characteristics. However, rechargeable $\mathrm{Mg}$ batteries are still in their infancy. Therefore, alternate $\mathrm{Mg}$-ion insertion anode materials are highly desirable to ultimately mass-produce rechargeable $\mathrm{Mg}$ batteries. In this study, we introduce the spinel $\mathrm{Li}_{4} \mathrm{Ti}_{5} \mathrm{O}_{12}$ as an Mg-ion insertion-type anode material with a high reversible capacity of $175 \mathrm{~mA} \mathrm{~h} \mathrm{~g}^{-1}$. This material possesses a low-strain characteristic, resulting in an excellent long-term cycle life. The proposed Mg-storage mechanism, including phase separation and transition reaction, is evaluated using advanced atomic scale scanning transmission electron microscopy techniques. This unusual $\mathrm{Mg}$ storage mechanism has rarely been reported for ion insertion-type electrode materials for rechargeable batteries. Our findings offer more options for the development of Mg-ion insertion materials for long-life rechargeable Mg batteries.

NPG Asia Materials (2014) 6, e120; doi:10.1038/am.2014.61; published online 22 August 2014

\section{INTRODUCTION}

With growing concern about the environment, climate change and a sustainable energy supply, studies have been focused on the development of green energy storage systems with high volumetric energy density, low price and improved safety. Compared to lithium battery systems, ${ }^{1-6}$ rechargeable magnesium $(\mathrm{Mg})$ batteries are considered to be a prospective candidate for reversible energy storage because of the great abundance of $\mathrm{Mg}$ resources, better chemical stability of metallic $\mathrm{Mg}$ in humid and oxygen-containing environments and higher volumetric capacity. ${ }^{7-9}$ In particular, the increasing attention to rechargeable $\mathrm{Mg}$ batteries is due to the pioneering work of Aurbach's group. ${ }^{10-14}$ Some progress has been achieved toward designing electrode materials ${ }^{10,15-24}$ and electrolytes ${ }^{25-29}$ for rechargeable $\mathrm{Mg}$ batteries. Nevertheless, rechargeable $\mathrm{Mg}$ batteries are still in their infancy. Therefore, alternative Mg-ion insertion anode materials are highly desirable to ultimately mass-produce rechargeable Mg-ion batteries. Recently, we have discovered the feasibility of utilizing spinel $\mathrm{Li}_{4} \mathrm{Ti}_{5} \mathrm{O}_{12}$, which is well known as a 'zero-strain' anode material for long-life stationary lithium-ion batteries, as an anode material for rechargeable $\mathrm{Mg}$ batteries. In this work, we further show that spinel $\mathrm{Li}_{4} \mathrm{Ti}_{5} \mathrm{O}_{12}$ nanoparticles (LTO NPs) can exhibit excellent $\mathrm{Mg}$ storage performance under optimized conditions for rechargeable $\mathrm{Mg}$ batteries. This material shows a high reversible capacity of $\sim 175 \mathrm{mAhg}^{-1}$ and superior cycling performance. By using an advanced atomic resolution scanning transmission electron microscopy (STEM) technique and inductively coupled-plasma atomic emission spectroscopy, it was found that this material exhibits an insertion-type Mg-ion storage capability through the gradual replacement of $\mathrm{Li}$ ions by $\mathrm{Mg}$ ions. This $\mathrm{Mg}$ insertion consequently transforms the LTO into spinel magnesium titanate. This mechanism is different from the classical $\mathrm{Li}^{+} / \mathrm{Na}^{+}$insertion/ extraction mechanism in LTO. ${ }^{30-35}$ Furthermore, the most desirable property of this material is that after the initial activation the volume change during the Mg-ion insertion and extraction is only $\sim 0.8 \%$, which shows the 'zero-strain' characteristics, thereby ensuring a long cycle life, as demonstrated by a good capacity retention of $>95 \%$ after 500 cycles. Our finding is a new mechanism of $\mathrm{Mg}$-ion storage in the LTO host lattice and offers an alternative Mg-ion insertion material for rechargeable $\mathrm{Mg}$ ion batteries.

\section{MATERIALS AND METHODS}

The LTO NPs were prepared by a facile sol-gel process. Li metal $(4 \mathrm{mM})$ was dissolved in $50 \mathrm{ml}$ of ethanol, forming a lithium ethoxide solution at ambient temperature. Pluronic F-127 (0.5 g) (Sigma-Aldrich Co. LLC., St Louis, MO, USA) was ultrasonically dissolved in the lithium ethoxide solution. Then, $5 \mathrm{~mm}$ of tetrabutyl titanate was thoroughly mixed in the solution. The solution (defined as A-solution) was mixed completely using a magnetic stirrer in a closed container placed in a dry environment for $\sim 6 \mathrm{~h}$ to avoid hydrolysis of tetrabutyl titanate with moisture. The A-solution turned into a more viscous pale brown solution (defined as B-solution) when heated at $40^{\circ} \mathrm{C}$ in a rotary

${ }^{1}$ CAS Key Laboratory of Molecular Nanostructure and Nanotechnology, and Beijing National Laboratory for Molecular Sciences, Institute of Chemistry, Chinese Academy of Sciences (CAS), Beijing, China; ${ }^{2}$ Beijing National Laboratory for Condensed Matter Physics, Institute of Physics, CAS, Beijing, China and ${ }^{3}$ Chemistry Department, Brookhaven National Laboratory, Upton NY, USA

Correspondence: Professor Y-G Guo, Institute of Chemistry, Chinese Academy of Sciences (CAS), No. 2, Zhongguancun First North Street, Beijing 100190, China or Professor L Gu or Professor H Li, Institute of Physics, CAS, Beijing 100190, China.

E-mail: ygguo@iccas.ac.cn or I.gu@iphy.ac.cn or hli@iphy.ac.cn

Received 5 March 2014; revised 19 May 2014; accepted 19 May 2014 
evaporator. A small amount of ethanol/water (v:v=1:1) mixed solution was spread on the bottom of the culture dish, then the B-solution was poured into the culture dish and dried in an oven at $100^{\circ} \mathrm{C}$ overnight. The light yellow power deposited at the bottom of the reactor was collected and heated at $400{ }^{\circ} \mathrm{C}$ for $10 \mathrm{~h}$ in a muffle furnace in air.

See the Supplementary Information for the detailed preparation methods of the $\mathrm{Mg}$ batteries and the structural and electrochemical characterization methods.

\section{RESULTS AND DISCUSSION}

Phase-pure LTO NPs were obtained by a facile sol-gel process, as confirmed by the X-ray diffraction (XRD) pattern of the as-prepared material (Supplementary Figure S1), with well-indexed peaks for the spinel LTO (JCPDS Card No. 49-0207, space group $\mathrm{Fd}_{3} \mathrm{~m}$ (227)). The electrochemical performance of the LTO NPs with an average particle size of $7-8 \mathrm{~nm}$ (Supplementary Figure S2) in rechargeable $\mathrm{Mg}$ batteries is shown in Figure 1. There is an activation process during the initial charging-discharging process, and the polarization decreases in the subsequent cycles (Figure 1a). The reversible capacity progressively increases during the first few cycles and ultimately reaches a stable maximum value of $175 \mathrm{mAhg}^{-1}$ in the 15 th cycle.
Note that the irreversible capacity is present only for the first few cycles, as nearly $100 \%$ Coulombic efficiency was obtained in the subsequent cycles. The irreversible capacity loss might have been caused by the formation of the solid electrolyte interphase layer (Supplementary Figure S3) when discharged to a lower voltage. On comparing the charge-discharge curves before and after the 15th cycle (Figures 1a and $1 \mathrm{~b}$ ), it was found that the typical electrochemical behavior of the cell, with a significant plateau (Figure 1a), gradually changes to a sloped discharge-charge voltage curve (Figure 1b), indicating that a complex reaction occurs during the $\mathrm{Mg}^{2}+$ insertion and extraction, which is different from the changes in $\mathrm{Li}^{+} / \mathrm{Na}^{+}$ storage in LTO. Figure 1c shows that the reversible capacity becomes lower at high current rates than at low current rates, implying that $\mathrm{Mg}$ diffusion in the host has relatively sluggish kinetics, ${ }^{15-18}$ which are related to the high polarizing power of a divalent $\mathrm{Mg}$ cation and further proven by the fact that larger LTO NPs (e.g., $15-20 \mathrm{~nm}$ ) deliver a much lower specific capacity (Supplementary Figure S4) than the LTO NPs in this work (ca. 7-8 nm). In addition, LTO NPs exhibit excellent cycling stability at various current densities (Figure 1d; Supplementary Figure S5). Under $300 \mathrm{mAg}^{-1},>95 \%$ of the maximum stable capacity was maintained after 500 cycles, and
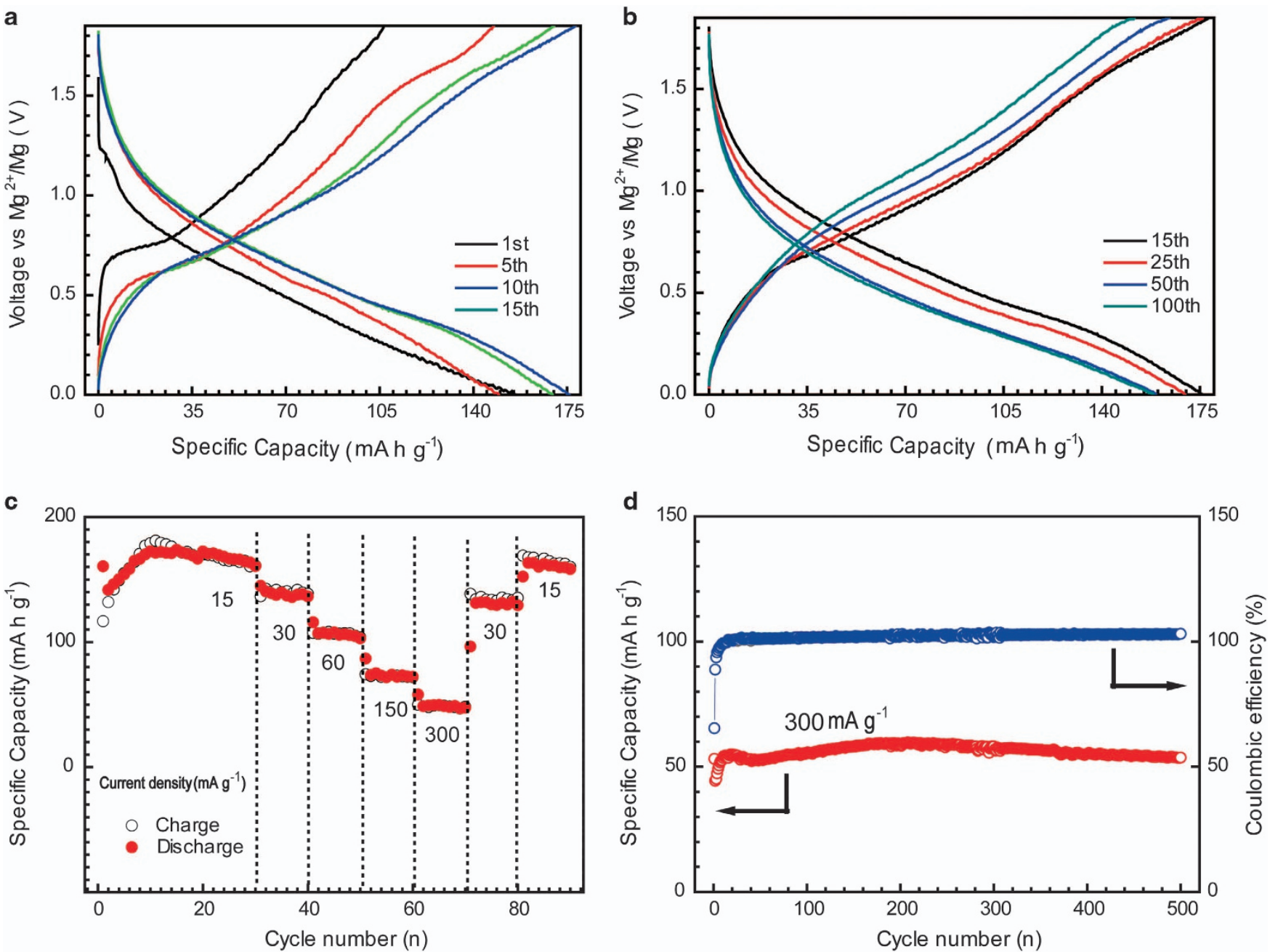

Figure 1 Charge-discharge characteristics of LTO electrodes in rechargeable Mg batteries (a, b). Typical galvanostatic discharge-charge voltage profiles of the cell cycled before (a) and after (b) 15 cycles at a current density of $15 \mathrm{mAg}^{-1}$. (c) Comparison of the rate capabilities of the cell cycled at different current densities. (d) Cycling performance of the cells using LTO electrodes cycled at a current density of $300 \mathrm{mAg}^{-1}$. 
the average Coulombic efficiency was close to $100 \%$. Such good cycling properties imply that LTO NPs might be a very attractive intercalated anode material for rechargeable Mg-ion batteries.

The steady-state cyclic voltammograms (CVs) of $\mathrm{Mg}$ insertion/ extraction into the LTO electrodes were obtained to study the $\mathrm{Mg}$ storage mechanism (Supplementary Figure S6). When the electrodes were discharged from an open circuit voltage to $0 \mathrm{~V}$, a peak at $\sim 1.1 \mathrm{~V}$ appears in the first cycle and disappears in the subsequent cycles (Supplementary Figure S6a), which might be caused by electrolyte decomposition at the electrode surfaces, corresponding to the initial capacity loss in Figure 1a. Another peak centered at $0.6 \mathrm{~V}$ is observed in the initial reduction process. This reduction peak can be ascribed to the Mg insertion into the LTO electrode. When the cell is charged from 0 to $1.85 \mathrm{~V}$ in the first cycle, $\mathrm{Li}$ ions are detected in the electrolyte, which suggests that some of the Li ions are released from the LTO electrode with the extraction of the $\mathrm{Mg}$ ions. Two main anodic peaks, at 0.8 and $1.7 \mathrm{~V}$, appear in the subsequent oxidation process. From the second reduction process, a new small reduction peak appears at $0.4 \mathrm{~V}$, following the main reduction peak at $0.7 \mathrm{~V}$. To check which redox peaks are associated with the insertion/extraction of the $\mathrm{Li}$ ions, we performed $\mathrm{CV}$ tests on the $\mathrm{LTO} / \mathrm{Mg}$ cell with $0.25 \mathrm{M}$ LiCl-Mg( $\left(\mathrm{AlCl}_{2} \mathrm{BuEt}_{2}\right)_{2} / \mathrm{THF}$ (Supplementary Figure S6c). From Supplementary Figure S6c, we can see clearly that when $\mathrm{LiCl}$ was added to the electrolyte the oxidation peak is centered at $0.8 \mathrm{~V}$ and that the new small reduction peak at $0.4 \mathrm{~V}$ increases sharply, whereas the oxidation peak at $1.7 \mathrm{~V}$ and the reduction peak at $0.7 \mathrm{~V}$ are almost unchanged. The significantly increased intensity of the redox peaks suggests that $\mathrm{Li}$ insertion and extraction in the LTO/Mg system occur at 0.4 and $0.8 \mathrm{~V}$, respectively. The increasing content of $\mathrm{Li}$ in the electrolyte in the activation process indicates that $\mathrm{Li}^{+}$ions released from the electrode in the charging process do not return to the electrode during the discharging process. This assumption is confirmed by the disappearance of the new small reduction peak at $0.4 \mathrm{~V}$ in the subsequent discharging process (Supplementary Figure S7a). Given that the intensity of the main oxidation peak at $1.7 \mathrm{~V}$ and the reduction peak at $0.7 \mathrm{~V}$ are negligibly affected by adding $\mathrm{LiCl}$ to the electrolyte (Supplementary Figure S6c), this pair of redox peaks can be ascribed solely to the extraction/insertion of $\mathrm{Mg}$ ions. Based on these results, we assume the Mg-ion extraction from LTO NPs has a two-stage process. The first stage of the Mg-ion extraction is at $0.8 \mathrm{~V}$, accompanying the co-extraction of the Li ions from LTO NPs, and the second stage of the Mg-ion extraction is at $\sim 1.7 \mathrm{~V}$. This hypothesis was confirmed by altering the voltage range of the $\mathrm{CV}$ test from $0-1.85 \mathrm{~V}$ to $0-1.2 \mathrm{~V}$ (Supplementary Figure S6b). When the measured voltage range changed from $0-1.2 \mathrm{~V}$ (for the initial three cycles) to $0-$ $1.85 \mathrm{~V}$ (for the fourth cycle), the main anodic peak at $\sim 1.7 \mathrm{~V}$ (Supplementary Figure S6b) appears sharply, and the intensity of the peak is almost as high as the fourth cycle (Supplementary Figure S6a). This finding indicates that the $\mathrm{Mg}$ ions in the second stage have been accumulating before the voltage reaches $1.5 \mathrm{~V}$. The increasing intensity of anodic peaks after the initial cycles is consistent with the activation process of LTO, as shown in Figure 1a. The above phenomenon can be observed more clearly in CV tests of the cells using LTO electrode materials with an average particle size of 15-20 nm (Supplementary Figure S7). The ICP results show the chemical composition of the electrode material after 100 charge-discharge cycles for three different states: $\mathrm{Mg}_{4} \mathrm{LiTi}_{5} \mathrm{O}_{12}$ (abbr. $\mathrm{Mg}_{4} \mathrm{Li}$, fully intercalated state), $\mathrm{Mg}_{3.25} \mathrm{Li}$ $\mathrm{Ti}_{5} \mathrm{O}_{12}$ (abbr. $\mathrm{Mg}_{3.25} \mathrm{Li}$, intermediate-deintercalated state), and $\mathrm{Mg}_{2.5} \mathrm{LiTi}_{5} \mathrm{O}_{12}$ (abbr. $\mathrm{Mg}_{2.5} \mathrm{Li}$, fully deintercalated state). (Detailed analysis is shown in the ICP experimental section.)
To further understand the features of Mg storage in LTO, in situ and ex situ XRD tests were performed (Figure 2). Both the in situ synchrotron XRD (Figure 2a) and ex situ XRD results (Figure 2b) show that the peak intensities of the cycled electrode increase slightly, but no pronounced peak shifts or new Bragg reflections were observed. It is well known that there is no obvious change in the XRD pattern during $\mathrm{Li}^{+}$insertion/extraction in LTO, which is the 'zero-strain' characteristic of $\mathrm{Li}$ insertion. ${ }^{30-33}$ The reason that no obvious new peaks were captured during the $\mathrm{Mg}^{2}+$ insertion/ extraction in the LTO might be attributed to the very closed ionic radii of the $\mathrm{Mg}$ ion $(0.062 \mathrm{~nm})$ and $\mathrm{Li}$ ion $(0.068 \mathrm{~nm})$. We believe that the excellent cycling stability of LTO in a Mg battery could benefit from the small volume changes during the charging-discharging process.

A density functional theory calculation was performed to study the change in the lattice parameters during $\mathrm{Mg}$ insertion-extraction. Figure 3 shows the configurations with the lowest total energy that we observed for $\mathrm{Mg}_{4} \mathrm{Li}$ and $\mathrm{Mg}_{2.5} \mathrm{Li}$, and the corresponding lattice constants for these configurations are listed in Table 1. The change in the lattice parameter of the charge-discharge products with reference to the initial state of the LTO was $<2.1 \%$. After the initial activation, the insertion-extraction of $\mathrm{Mg}^{2+}$ occurred reversibly between $\mathrm{Mg}_{4} \mathrm{Li}$ and $\mathrm{Mg}_{2.5} \mathrm{Li}$, which resulted in a change in the lattice constant for this process of only $\sim 0.8 \%$. The results indicate that the 'zero-strain' characteristic of this material is preserved not only as an anode for the Li-ion battery but also for the Mg-ion battery.

Because the XRD is insensitive to subtle structural changes owing to the 'zero-strain' characteristic of LTO during $\mathrm{Mg}^{2+}$ insertionextraction, STEM techniques were carried out to further study the complex chemical reactions during the $\mathrm{Mg}^{2+}$ insertion and extraction. Figures $4 \mathrm{a}$ and $\mathrm{b}$ show the LTO (abbr. Li4) lattice and the corresponding HAADF and ABF STEM images viewed along the [110] direction, respectively. By comparing the repeat unit in Figure $4 \mathrm{~b}$ with Figure $4 \mathrm{a}$, the 32e oxygen sites and 16d titanium sites can be clearly seen in the HAADF image. Because $\mathrm{Li} 4$ and $\mathrm{Li}_{7} \mathrm{Ti}_{5} \mathrm{O}_{12}$ (abbr. Li7) have an almost identical $\left[\mathrm{Ti}_{5} \mathrm{Li}\right]^{16 \mathrm{~d}} \mathrm{O}_{12}$ host, they are nearly indistinguishable in the HAADF images because there is no contrast in the $\mathrm{Li}$ columns. However, in the ABF images and corresponding line profiles, the Li contrasts can be identified by the $8 \mathrm{a}$ (Figure $4 \mathrm{~b}$ ) and $16 \mathrm{c}$ sites (Figure $4 \mathrm{c}$ ) for Li4 and Li7, respectively. After the Li4 electrode was discharged to $0 \mathrm{~V}$ in the first cycle, the Li7 phases (Figure 4c) and a new phase (Figure 4d), which is distinguishable from both the Li4 and Li7 phases, are observed at the same time. In the new phase, a significant contrast is observed at the $16 \mathrm{c}$ site (Figure $4 \mathrm{~d}$ ), meaning that atoms with a large atomic number, $Z$, emerged at the $16 \mathrm{c}$ sites, and the corresponding line profile gives a much clearer picture of the $\mathrm{Mg}^{2+}$ position. Hence it is reasonable to conclude that $\mathrm{Mg}^{2}+$ occupies the $16 \mathrm{c}$ sites after $\mathrm{Mg}$ insertion. These observations preliminarily confirm that the $\mathrm{Mg}$ insertion process is analogous to the Li insertion process. However, in the initial charged samples, $\mathrm{Mg}$ ions are clearly observed at both the $8 \mathrm{a}$ and $16 \mathrm{c}$ sites in the HAADF/ABF image of the initial half-charged (Figure 4e) and fully charged (Figure 4f) samples.

We also investigated the samples at different charge-discharge states after 100 cycles by using the STEM technique (Supplementary Figure S8). In the fully discharged sample, a single phase with $\mathrm{Mg}$ ions occupying the $16 \mathrm{c}$ sites was observed (Supplementary Figures S8a-c). A different homogeneous phase, with $\mathrm{Mg}^{2+}$ at both the $8 \mathrm{a}$ and $16 \mathrm{c}$ sites (Supplementary Figures S8g-i), was observed in the fully charged sample. By contrast, in the half-charged sample, two phases with $\mathrm{Mg}^{2+}$ at different sites are identified (Supplementary Figures S8d-f). 
a

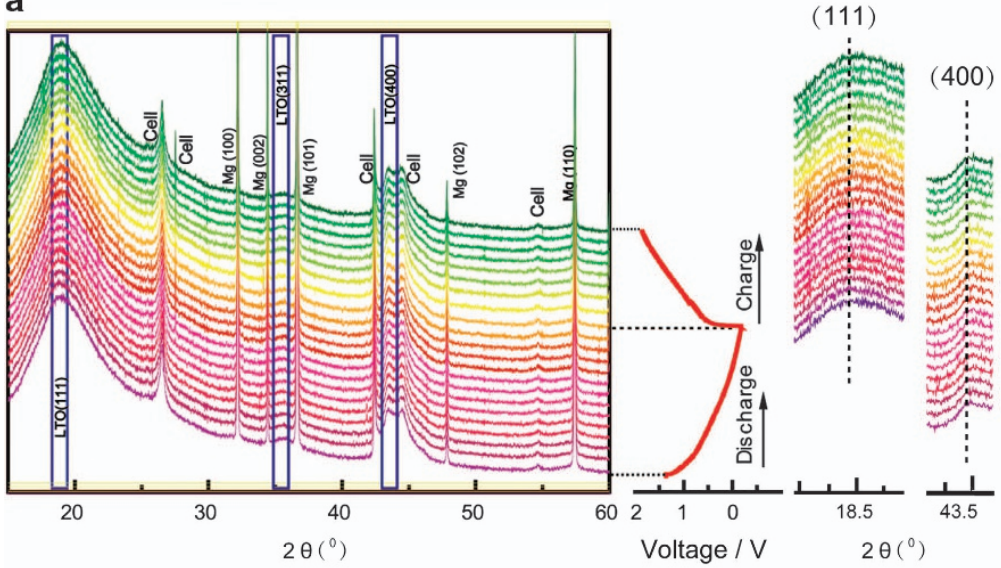

b

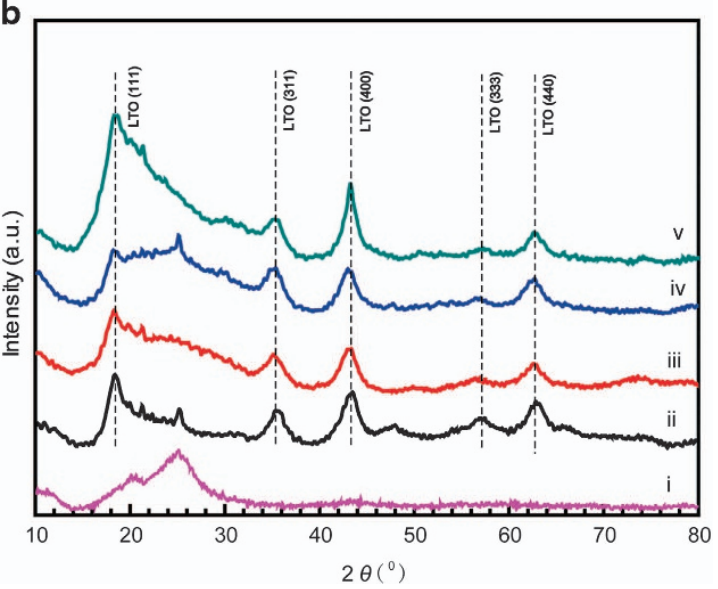

Figure 2 XRD patterns: (a) in situ XRD patterns collected during the first discharge-charge of the LTO/Mg cell under a current rate of C/10 at a voltage between 0 and $1.85 \mathrm{~V}$; and (b) ex situ XRD patterns of the LTO electrode at different charged-discharged states where (i) the mixture of super-P/PVDF was used to prepare the working electrode and a Kapton film was used to cover the electrode; (ii) the as-prepared electrode; (iii) the electrode at the 100th fully discharged state; (iv) the electrode at the 100th half-charged state; and (v) the electrode at the 100th fully charged state.

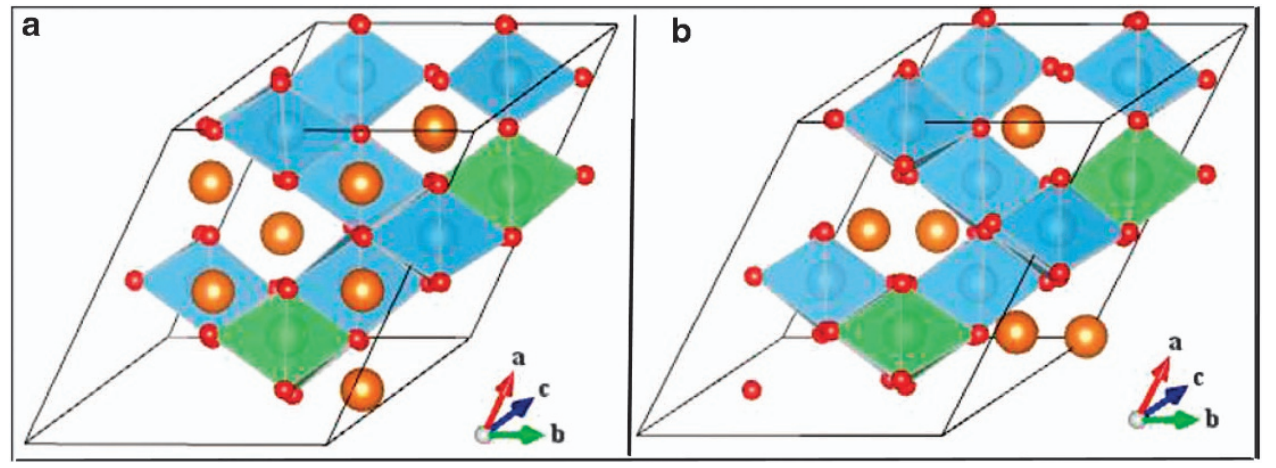

Figure 3 The most stable cell for (a) Mg4Li and (b) Mg2.5Li among the calculated top 30 configurations with low electrostatic interaction energy. The green, orange, blue and red bullets indicate $\mathrm{Li}, \mathrm{Mg}$, $\mathrm{Ti}$ and $\mathrm{O}$ atoms, respectively.

Table 1 The optimized lattice constant for LTO, Li7 and Mg4Li, and Mg2.5 Li

\begin{tabular}{lclll}
\hline Phase & Li4 & Li7 & Mg4Li & Mg2.5Li \\
\hline$a(\AA)$ & 8.506 & 8.52 & 8.679 & 8.605 \\
$\Delta a(\%)$ & - & 0.19 & 2.03 & 1.16 \\
\hline
\end{tabular}

The percentage change of the lattice constant $\Delta \mathrm{a}(\%)$ refers to the lattice parameter of LTO.

Neither Li4 nor Li7 was observed in the samples. These results imply that the Mg storage mechanism in LTO is different from the classical $\mathrm{Li}^{+} / \mathrm{Na}^{+}$storage mechanism in LTO.

Based on the above analysis, we propose a possible Mg storage mechanism in a small LTO nanoparticle, as shown in Figure 5. Electrochemical measurements show that $\mathrm{Mg}$ ions can indeed be inserted into LTO (Supplementary Figures S6 and S7), whereas elemental analysis of the electrolyte and the counter electrode indicates that no lithium was released during the first cycle of discharging. Thus, $\mathrm{Mg}^{2+}$ insertion is expected to be analogous to the insertion process of $\mathrm{Li}^{+} / \mathrm{Na}^{+}{ }^{30-35}$ At the beginning of the first $\mathrm{Mg}$ insertion process, $\mathrm{Mg}$ ions are more likely to occupy the $16 \mathrm{c}$ sites of the Li4 phase (where the $\mathrm{Li}^{16 \mathrm{~d}}$ ions are nearly fixed) to form the $\mathrm{Mg} 4 \mathrm{Li}$ phase. At the same time, the $\mathrm{Li}^{8 \mathrm{a}}$ ions, accompanying the other Li ions in the $8 \mathrm{a}$ sites of the nearest-neighbor Li4 phase, are pushed by $\mathrm{Mg}^{2}+$ to the $16 \mathrm{c}$ sites of the nearest-neighbor Li4 phase to form the new Li7 phase. Consequently, two new phases (Mg4Li and Li7) are created (Figure 5a), as confirmed by the STEM techniques (Figures $4 \mathrm{c}$ and d). With further discharge, $\mathrm{Mg}$ insertion will take place on the $\mathrm{Mg} 4 \mathrm{Li} / \mathrm{Li} 7$ boundary and simultaneously push the $\mathrm{Li}^{16 \mathrm{c}}$ ions from the newly formed Li7 phase into the nearby Li4 phase to grow more of the Li7 phase. In an ideal equilibrium situation, only the Li7 and Mg4Li phases coexist in the electrode at the end of the first discharge. The direct observation of the three-phase coexistence interface (Mg4Li/Li7 and Li7/Li4, Supplementary Figure S9) agrees well with the completion of the initial insertion process. The reactions of the insertion process in the 1 st cycle can be defined as shown in equation (1) ( $\square$ : vacancy):

$$
\begin{aligned}
& 2\left[\mathrm{Li}_{3}\right]^{8 \mathrm{a}} \square^{16 \mathrm{c}}\left[\mathrm{Ti}_{5} \mathrm{Li}\right]^{16 \mathrm{~d}} \mathrm{O}_{12}+4 \mathrm{Mg}^{2+}+8 \mathrm{e}^{-} \\
& \rightarrow \square^{8 \mathrm{a}}\left[\mathrm{Mg}_{4}\right]^{16 \mathrm{c}}\left[\mathrm{Ti}_{5} \mathrm{Li}\right]^{16 \mathrm{~d}} \mathrm{O}_{12}+\square^{8 \mathrm{a}}\left[\mathrm{Li}_{6}\right]^{16 \mathrm{c}}\left[\mathrm{Ti}_{5} \mathrm{Li}\right]^{16 \mathrm{~d}} \mathrm{O}_{12}
\end{aligned}
$$

In the subsequent $\mathrm{Mg}$ extraction process (Figure $5 \mathrm{~b}$ ), for the $\mathrm{Mg} 4 \mathrm{Li}$ phase, a portion of the $\mathrm{Mg}^{16 \mathrm{c}}$ ions are extracted while some $\mathrm{Mg}$ ions 
a
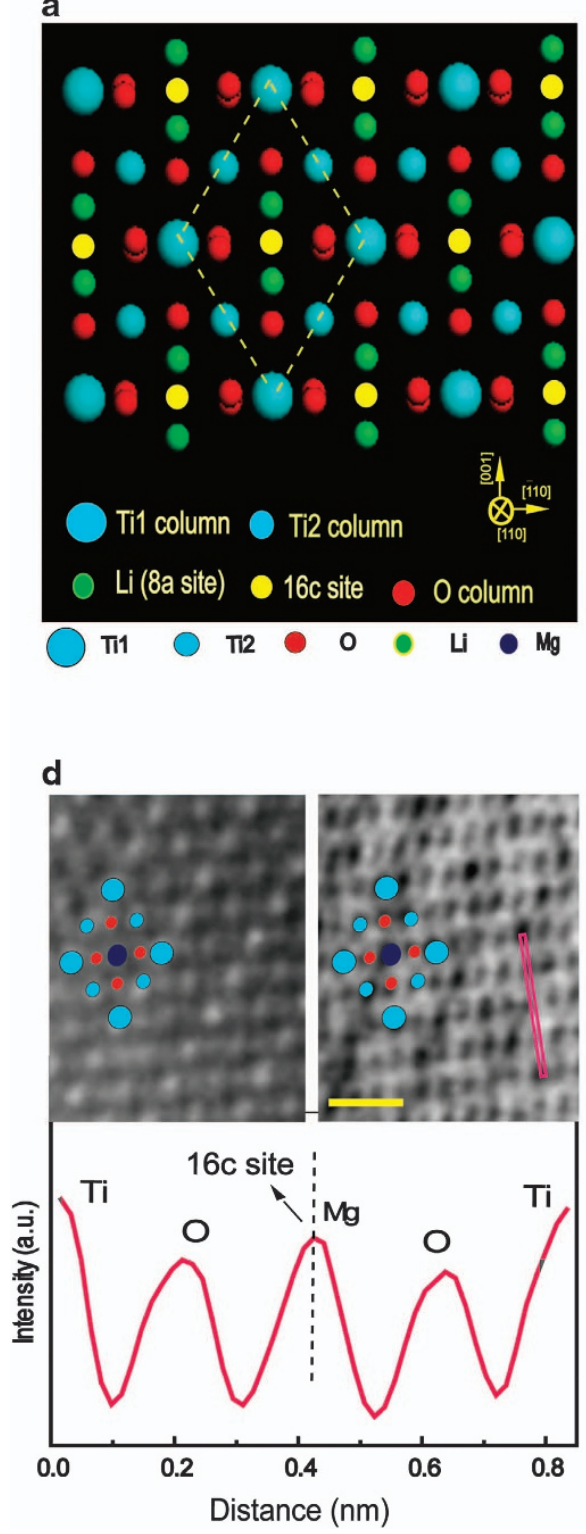

b

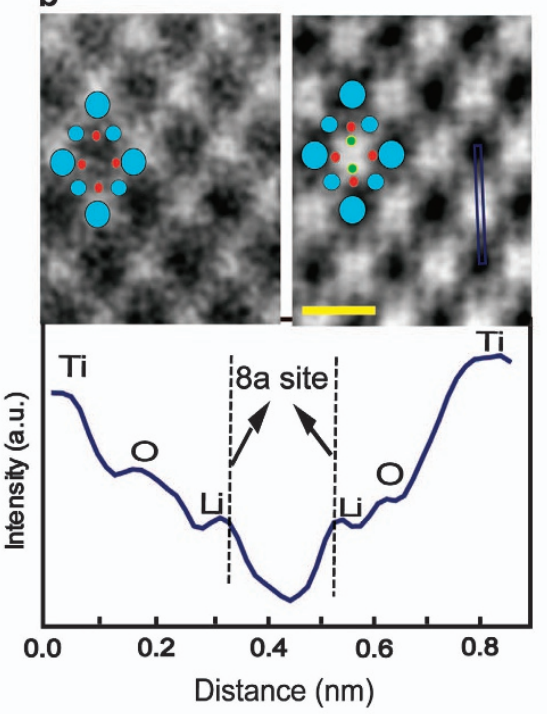

e

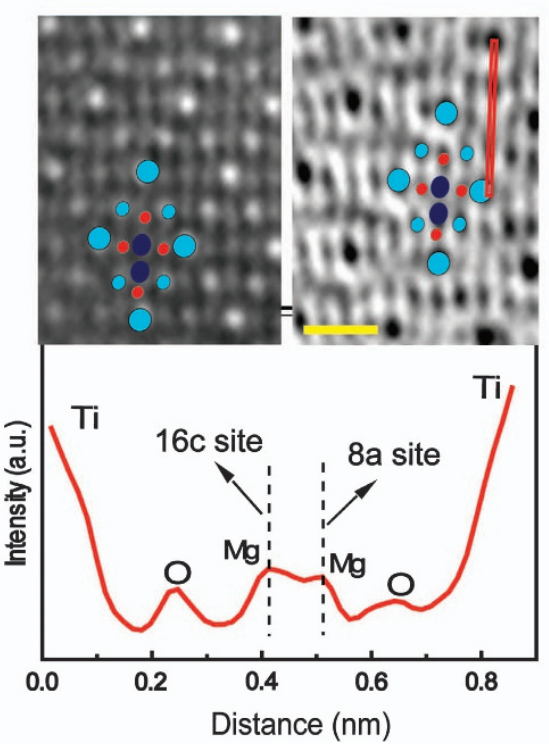

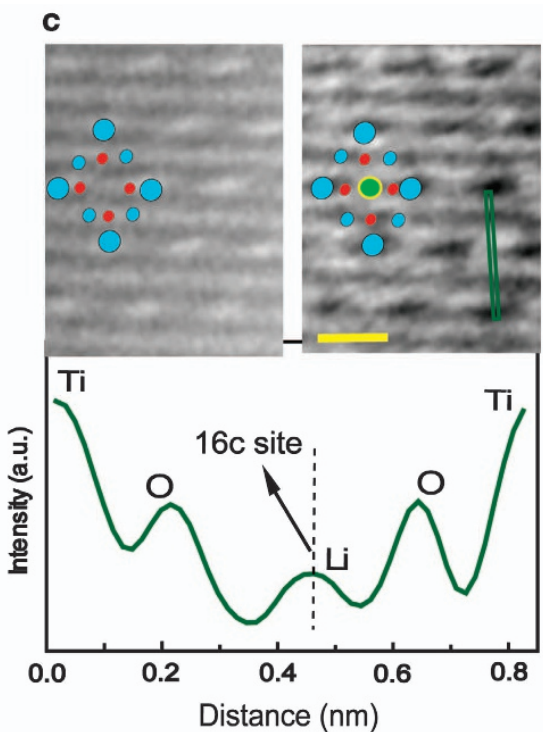

f

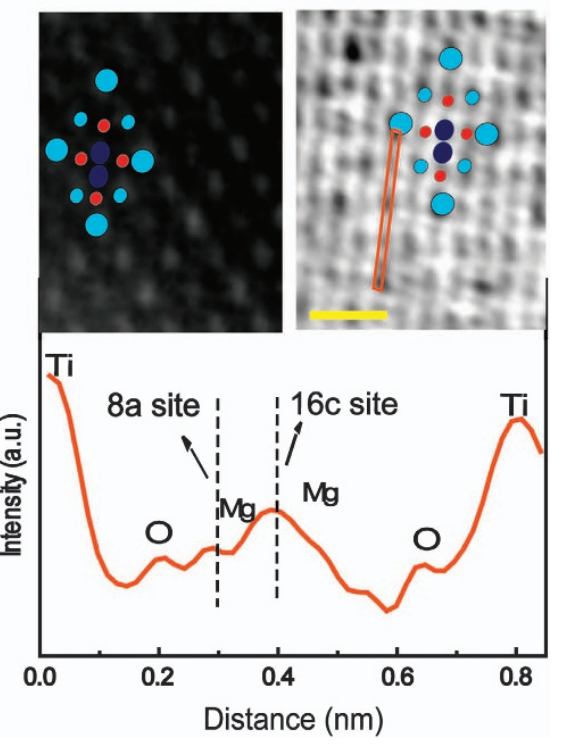

Figure 4 (a) Schematic lattice of spinel Li4 viewed from the [110] zone axis, where the Ti, O, Li (8a-sites) and Li (16c-sites) columns are highlighted with light blue, red, green and yellow, respectively. (b) HAADF, ABF images and ABF line profile for Li4 phase. (c) The sample at the first fully discharged state with the Li7 phase and (d) Mg4Li phase. (e) The sample at the first half-charged state and (f) the sample at the first fully charged state. Note that the image contrast of the dark dots is inverted and displayed as peaks in the ABF line profile. Scale bar equals $0.5 \mathrm{~nm}$.
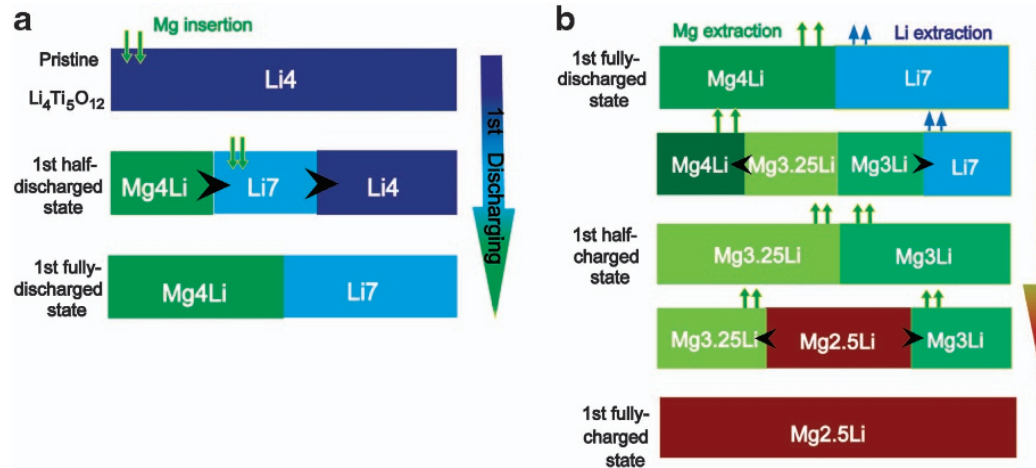
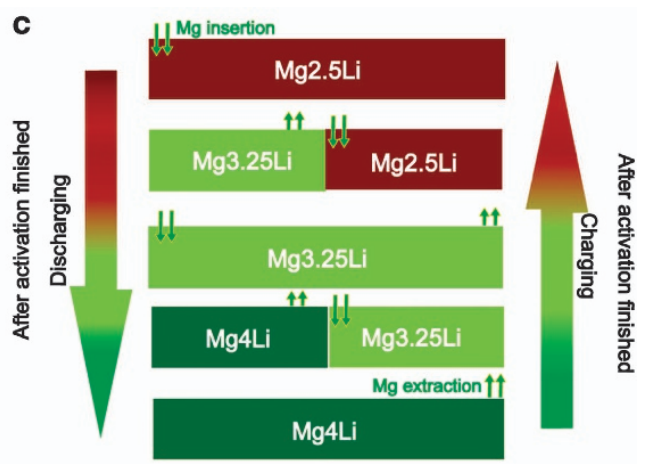

Figure 5 (a) The 1st cycle of the discharging and (b) charging processes in the Mg battery. (c) The discharge-charge processes after activation had finished in the $\mathrm{Mg}$ battery. Directions of phase boundary movement are marked by colored arrows. 
fill the 8a sites, forming the Mg3.25Li phase. The transformation from the $\mathrm{Mg} 4 \mathrm{Li}$ to the $\mathrm{Mg} 3.25 \mathrm{Li}$ phase is similar to the reaction from $\mathrm{Li} 7$ to Li4. ${ }^{29,31}$ However, for the Li7 phase, the $\mathrm{Li}^{16 \mathrm{c}}$ ions are extracted but cannot fill the $8 \mathrm{a}$ sites. Then, $\mathrm{Mg}$ ions instead of $\mathrm{Li}$ ions fill the $8 \mathrm{a}$ sites and $16 \mathrm{c}$ sites, forming the $\mathrm{Mg} 3 \mathrm{Li}$ phase. As the charging voltage increases, some $\mathrm{Mg}^{8 \mathrm{a}}$ ions in both the $\mathrm{Mg} 3.25 \mathrm{Li}$ and $\mathrm{Mg} 3 \mathrm{Li}$ phases begin to be extracted, and these two Mg-'rich' phases $(\mathrm{Mg} 3.25 \mathrm{Li}$ and $\mathrm{Mg} 3 \mathrm{Li})$ are transformed to a phase containing less $\mathrm{Mg}(\mathrm{Mg} 2.5 \mathrm{Li})$ at the end of the charging process. The above charging process during the first cycle could be defined as in Equation (2) and Equation (3), respectively:

$$
\begin{aligned}
& \square^{8 \mathrm{a}}\left[\mathrm{Mg}_{4}\right]^{16 \mathrm{c}}\left[\mathrm{Ti}_{5} \mathrm{Li}^{16 \mathrm{~d}} \mathrm{O}_{12} \rightarrow\left[\mathrm{Mg}_{3.25-x}\right]^{8 \mathrm{a}}\left[\mathrm{Mg}_{x}\right]^{16 \mathrm{c}}\left[\mathrm{Ti}_{5} \mathrm{Li}\right]^{16 \mathrm{~d}} \mathrm{O}_{12}\right. \\
& \left.+0.75 \mathrm{Mg}^{2+}+1.5 \mathrm{e}^{-} \text {(half-deintercalated state, } 0<x<2.5\right) \\
& \rightarrow\left[\mathrm{Mg}_{2.5-x}\right]^{8 \mathrm{a}}\left[\mathrm{Mg}_{x}\right]^{16 \mathrm{c}}\left[\mathrm{Ti}_{5} \mathrm{Li}\right]^{16 \mathrm{~d}} \mathrm{O}_{12}+1.5 \mathrm{Mg}^{2+}+3 \mathrm{e}^{-}
\end{aligned}
$$

(fully deintercalated state, $0<x<2.5$ )

$$
\begin{aligned}
& \square^{8 \mathrm{a}}\left[\mathrm{Li}_{6}\right]^{16 \mathrm{c}}\left[\mathrm{Ti}_{5} \mathrm{Li}\right]^{16 \mathrm{~d}} \mathrm{O}_{12}+3 \mathrm{Mg}^{2+} \rightarrow 6 \mathrm{Li}^{+}+\left[\mathrm{Mg}_{3-x}\right]^{8 \mathrm{a}} \\
& \left.\left[\mathrm{Mg}_{x}\right]^{16 \mathrm{c}}\left[\mathrm{Ti}_{5} \mathrm{Li}\right]^{16 \mathrm{~d}} \mathrm{O}_{12} \text { (half-deintercalated state, } 0<x<2.5\right) \\
& \rightarrow 6 \mathrm{Li}^{+}+0.5 \mathrm{Mg}^{2+}+\mathrm{e}^{-}+\left[\mathrm{Mg}_{2.5-x}\right]^{8 \mathrm{a}}\left[\mathrm{Mg}_{x}\right]^{16 \mathrm{c}}\left[\mathrm{Ti}_{5} \mathrm{Li}^{16 \mathrm{~d}} \mathrm{O}_{12}\right.
\end{aligned}
$$

(fully deintercalated state, $0<x<2.5$ )

It is clear that the irreversible transformation of Li7 into spinel magnesium titanate starts from the early stage of the charging process. This irreversible phase transformation process corresponds to the activation process of the electrode material. Only spinel magnesium titanates $\left(\mathrm{Mg}_{4} \mathrm{Li}, \mathrm{Mg}_{3.25} \mathrm{Li}\right.$ and $\left.\mathrm{Mg} 2.5 \mathrm{Li}\right)$ are obtained in the electrodes after the initial activation. Then, a clearly different electrochemical reaction takes place in the subsequent process (Figure $5 \mathrm{c}$ ). The as-formed $\mathrm{Mg}_{4} \mathrm{Li}$ and $\mathrm{Mg}_{2.5} \mathrm{Li}$ phases serve as the active material to insert-extract $\mathrm{Mg}^{2}+$ in a highly reversible fashion after the activation process. The specific reactions are defined in equation (4):

$$
\begin{aligned}
& \square^{8 \mathrm{a}}\left[\mathrm{Mg}_{4}\right]^{16 \mathrm{c}}\left[\mathrm{Ti}_{5} \mathrm{Li}\right]^{16 \mathrm{~d}} \mathrm{O}_{12} \leftrightarrow\left[\mathrm{Mg}_{3.25-x}\right]^{8 \mathrm{a}}\left[\mathrm{Mg}_{x}\right]^{16 \mathrm{c}}\left[\mathrm{Ti}_{5} \mathrm{Li}\right]^{16 \mathrm{~d}} \mathrm{O}_{12} \\
& \left.+0.75 \mathrm{Mg}^{2+}+1.5 \mathrm{e}^{-} \text {(half-deintercalated state, } 0<x<2.5\right) \\
& \leftrightarrow\left[\mathrm{Mg}_{2.5-x}\right]^{8 \mathrm{a}}\left[\mathrm{Mg}_{x}\right]^{16 \mathrm{c}}\left[\mathrm{Ti}_{5} \mathrm{Li}\right]^{16 \mathrm{~d}} \mathrm{O}_{12}+1.5 \mathrm{Mg}^{2+}+3 \mathrm{e}^{-}
\end{aligned}
$$

(fully deintercalated state, $0<x<2.5$ )

XPS and EDX mapping analysis of the ex situ electrodes at different charge/discharge states (Supplementary Figure S10) further confirm the phase transition mechanism.

In conclusion, we have demonstrated that spinel LTO could be utilized as a $\mathrm{Mg}^{2+}$ insertion-type anode material for a nextgeneration Mg-ion battery and have proposed an unusual phase separation and transition mechanism. The phase boundaries, as well as the process of $\mathrm{Mg}^{2}+$ gradually extruding $\mathrm{Li}^{+}$from the lattice, were clearly visualized at the atomic scale. Moreover, this material can deliver a high capacity of up to $175 \mathrm{~mA} \mathrm{hg}^{-1}$, corresponding to 1.5 $\mathrm{Mg}$ per formula unit, and a long cycle life, as demonstrated by the small capacity decay of $0.01 \%$ per cycle over 500 cycles. These desirable properties are benefited from the low-strain characteristics of LTO. Compared to the different strain behaviors of the insertion of $\mathrm{Li}, \mathrm{Mg}$ and $\mathrm{Na}$, the current findings reinforce the idea that the diameter of guest cations also plays an important role in maintaining low or zero strain of the host lattice. In addition, the impressive Mgion insertion properties of the nanosized LTO indicate remarkable nanometer size effects towards $\mathrm{Mg}$ storage, ${ }^{36}$ which will trigger people to reinvestigate materials that were thought to be electrochemically inactive in bulk form due to poor kinetics, but that could present improved Mg-ion insertion capability at the nanoscale.

\section{ACKNOWLEDGEMENTS}

This work was supported by the National Natural Science Foundation of China (Grant Nos. 51225204, 21303222 and 21127901), the National Basic Research Program of China (Grant Nos. 2011CB935700 and 2012CB932900) and the 'Strategic Priority Research Program' of the Chinese Academy of Sciences (Grant No. XDA09010000). The work at BNL was supported by the US Department of Energy, the Assistant Secretary for Energy Efficiency and Renewable Energy, and the Office of Vehicle Technologies (DE-AC0298CH10886). We acknowledge the technical support from a beamline scientist at the X-ray beamline X14A (NSLS, BNL) and 11-BM-B (APS, ANL). We thank Dr Yong-Qing Wang for help with material syntheses, Dr Xing-Long Wu for help with battery tests and Prof. Yongsheng Hu for helpful discussions.

Author contributions: Y-GG and NW designed this work; Y-GG and Y-XY proposed and supervised the project; NW synthesized the materials, carried out the electrochemical tests and main materials characterizations (including the ICP experiments and ex situ characterizations) with Y-XY; LG performed the STEM imaging and analyzed the images with NW and YL; R-JX performed the DFT calculations; XY performed the in situ synchrotron XRD measurements with X-QY; NW, Y-XY, Y-GG, HL, LG and X-QY wrote the paper; all authors participated in the analysis of the experimental data and discussions of the results, as well as in preparing the paper.

1 Tarascon, J. M. \& Armand, M. Issues and challenges facing rechargeable lithium batteries. Nature 414, 359-367 (2001).

2 Goodenough, J. B. \& Kim, Y. Challenges for rechargeable Li batteries. Chem. Mater 22, 587-603 (2010)

3 Xu, X., Luo, Y. Z., Mai, L. Q., Zhao, Y. L., An, Q. Y., Xu, L., Hu, F., Zhang, L. \& Zhang, Q. J. Topotactically synthesized ultralong LiV308 nanowire cathode materials for high-rate and long-life rechargeable lithium batteries. NPG Asia Mater. 4, e20 (2012).

4 Zhang, T. \& Zhou, H. S. A reversible long-life lithium-air battery in ambient air. Nat. Commun. 4, 1817 (2013).

5 Thomas, J. Lithium batteries-A spectacularly reactive cathode. Nat. Mater. 2, 705-706 (2003)

6 Pasta, M., Wessells, C. D., Huggins, R. A. \& Cui, Y. A high-rate and long cycle life aqueous electrolyte battery for grid-scale energy storage. Nat. Commun. 3, 1149 (2012)

7 Aurbach, D., Schechter, A., Chusid, O., Gizbar, H., Cohen, Y., Ashkenazi, V. Moshkovich, M., Turgeman, R. \& Levi, E. A short review on the comparison between Li battery systems and rechargeable magnesium battery technology. J. Power Sources 97-98, 28-32 (2001).

8 Chen, X. Z. \& Hong, L. i. Thermodynamic analysis on energy densities of batteries Energy Environ. Sci. 4, 2614-2624 (2011).

9 Novak, P., Imhof, R. \& Haas, O. Magnesium insertion electrodes for rechargeable nonaqueous batteries- a competitive alternative to lithium? Electrochim. Acta 45, 351-367 (1999).

10 Aurbach, D., Lu, Z., Schechter, A., Gofer, Y., Gizbar, H., Turgeman, R., Cohen, Y., Moshkovich, M. \& Levi, E. Prototype systems for rechargeable magnesium batteries. Nature 407, 724-727 (2000)

11 Amir, N., Vestfrid, Y., Chusid, O., Gofer, Y. \& Aurbach, D. Progress in nonaqueous magnesium electrochemistry. J. Power Sources 174, 1234-1240 (2007).

12 Aurbach, D., Weissman, I., Gofer, Y. \& Levi, E. Nonaqueous magnesium electrochem istry and its application in secondary batteries. Chem. Rec. 3, 61-73 (2003).

13 Chusid, O., Gofer, Y., Gizbar, H., Vestfrid, Y., Levi, E., Aurbach, D. \& Riech, I. Solidstate rechargeable magnesium batteries. Adv. Mater. 15, 627-630 (2003).

14 Aurbach, D., Suresh, G. S., Levi, E., Mitelman, A., Mizrahi, O., Chusid, O. \& Brunelli, M. Progress in rechargeable magnesium battery technology. Adv. Mater. 19, 4260-4267 (2007)

15 Levi, E., Gofer, Y. \& Aurbach, D. On the way to rechargeable Mg batteries: the challenge of new cathode materials. Chem. Mater. 22, 860-868 (2010).

16 Levi, E., Mitelman, A., Aurbach, D. \& Brunelli, M. Structural mechanism of the phase transitions in the Mg-Cu-Mo6S8 system probed by ex situ synchrotron X-ray diffraction. Chem. Mater. 19, 5131-5142 (2007).

17 Imamura, D., Miyayama, M., Hibino, M. \& Kudo, T. Mg intercalation properties into V205 gel/carbon composites under high-rate condition. J. Electrochem. Soc. 150, A753-A758 (2003)

18 Tao, Z. L., Xu, L. N., Gou, X. L., Chen, J. \& Yuan, H. T. TiS2 nanotubes as the cathode materials of Mg-ion batteries. Chem. Commun. 18, 2080-2081 (2004).

$19 \mathrm{NuLi}$, Y., Yang, J., Wang, J. \& Li, Y. Electrochemical intercalation of Mg2 + in magnesium manganese silicate and its application as high-energy rechargeable magnesium battery cathode. J. Phys. Chem. C 113, 12594-12597 (2009).

20 Liang, Y., Feng, R. J., Yang, S. Q., Ma, H., Liang, J. \& Chen, J. Rechargeable Mg batteries with graphene-like MoS2 cathode and ultrasmall Mg nanoparticle anode. Adv Mater. 23, 640-643 (2011).

21 Arthur, T. S., Singh, N. \& Matsui, M. Electrodeposited Bi, Sb and Bi1-xSbx alloys as anodes for Mg-ion batteries. Electrochem. Commun. 16, 103-106 (2012). 
22 Singh, N., Arthur, T. S., Chen, L., Matsui, M. \& Mizuno, F. A high energy-density tin anode for rechargeable magnesium-ion batteries. Chem. Commun. 49, 149-151 (2013).

23 Shao, Y. Y., Gu, M., Li, X. L., Nie, Z., Zuo, P. J., Li, G. S., Liu, T. B., Xiao, J., Cheng, Y. W., Wang, C., Zhang, J. G. \& Liu, J. Highly reversible Mg insertion in nanostructured Bi for Mg ion batteries. Nano Lett. 14, 255-260 (2014).

24 Mitelman, A., Levi, M. D., Lancry, E., Levi, E. \& Aurbach, D. New cathode materials for rechargeable $\mathrm{Mg}$ batteries fast $\mathrm{Mg}$ ion transport and reversible copper extrusion in CuMo6S8 compounds. Chem. Commun. 41, 4212-4214 (2007).

25 Kumar, G. G. \& Munichandraiah, N. Solid-state rechargeable magnesium cell with poly (vinylidenefluoride)-magnesium triflate gel polymer electrolyte. J. Power Sources 102, 46-54 (2001).

26 Pour, N., Gofer, Y., Major, D. T. \& Aurbach, D. Structural analysis of electrolyte solutions for rechargeable Mg batteries by stereoscopic means and DFT calculations. J. Am. Chem. Soc. 133, 6270-6278 (2011).

27 Yoshimoto, N., Yakushiji, S. \& Ishikawa, M. Rechargeable magnesium batteries with polymeric gel electrolytes containing magnesium salts. Electrochim. Acta 48, 2317-2322 (2003)

28 Oh, J. S., Ko, J. M. \& Kim, D. W. Preparation and characterization of gel polymer electroIytes for solid state magnesium batteries. Electrochim. Acta 50, 903-906 (2004).

29 Aurbach, D., Schechter, A., Moshkovich, M., Chusid, O., Gottlieb, H. E., Gofer, Y. \& Goldberg, I. Electrolyte solutions for rechargeable magnesium batteries based on organomagnesium chloroaluminate complexes. J. Electrochem. Soc. 149, A115-A121 (2002).

30 Laumann, A., Boysen, H., Bremholm, M., Fehr, K. T., Hoelzel, M. \& Holzapfe, M. Lithium migration at high temperatures in Li4Ti5012 studied by neutron diffraction. Chem. Mater. 23, 2753-2759 (2011).

31 Yu, X. Q., Pan, H. L., Wan, W., Ma, C., Bai, J. M., Meng, Q. P., Ehrlich, S. N., Hu, Y. S. \& Yang, X. Q. A size-dependent sodium storage mechanism in Li4Ti5012 investigated by a novel characterization technique combining in Situ X-ray diffraction and chemical sodiation. Nano. Lett. 13, 4721-4727 (2013)
32 Kitta, M., Akita, T., Tanaka, S. \& Kohyama, M. Characterization of two phase distribution in electrochemically-lithiated spinel Li4Ti5012 secondary particles by electron energy-loss spectroscopy. J. Power Sources 237, 26-32 (2013).

33 Lu, X., Zhao, L., He, X. Q., Xiao, R. J., Gu, L., Hu, Y. S., Li, H., Wang, Z. X., Duan, X. F., Chen, L. Q., Maier, J. \& Ikuhara, Y. Lithium storage in Li4Ti5012 Spinel: the full static picture from electron microscopy. Adv. Mater. 24, 3233-3238 (2012).

34 Sun, Y., Zhao, L., Pan, H. L., Lu, X., Gu, L., Hu, Y. S., Li, H., Armand, M., Ikuhara, Y. Chen, L. Q. \& Huang, X. J. Direct atomic-scale confirmation of new three-phase storage mechanism in Li4Ti5012 anode for room-temperature sodium-ion batteries. Nat. Commun. 4, 1870 (2013).

35 Liu, J., Tang, K., Song, K., van Aken, P. A., Yu, Y. \& Maier, J. Tiny Li4Ti5012 nanoparticles embedded in carbon nanofibers as high-capacity and long-life anode materials for both Li-ion and Na-ion batteries. Phys. Chem. Chem. Phys. 15, 20813-20818 (2013)

$36 \mathrm{Wu}$, N., Yin, Y. X. \& Guo, Y. G. Size-dependent electrochemical magnesium storage performance of spinel lithium titanate. Chem. Asian J. (e-pub ahead of print 6 June 2014; doi:10.1002/asia.201402286)

(c) (i) $\odot$ This work is licensed under a Creative Commons Attribution-NonCommercial-NoDerivs 3.0 Unported License. The images or other third party material in this article are included in the article's Creative Commons license, unless indicated otherwise in the credit line; if the material is not included under the Creative Commons license, users will need to obtain permission from the license holder to reproduce the material. To view a copy of this license, visit http://creativecommons.org/licenses/by-nc-nd/3.0/

Supplementary Information accompanies the paper on the NPG Asia Materials website (http://www.nature.com/am) 